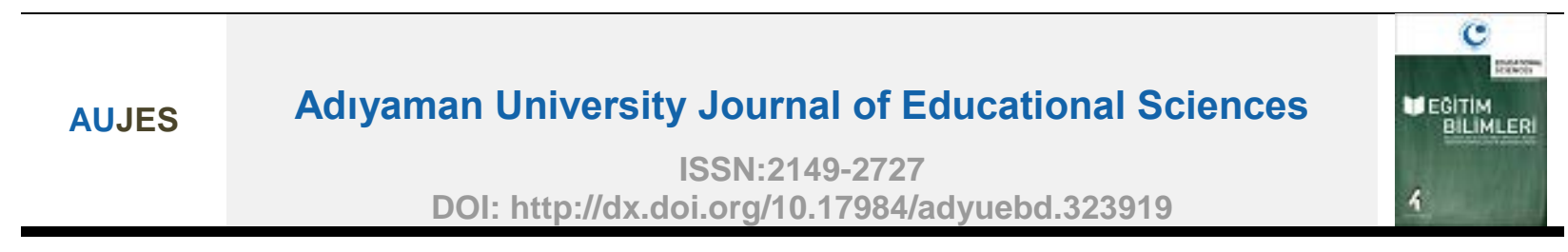

\title{
Relations between Executive Functions and Intelligence in Gifted Children
}

\author{
Ahmet BiLDiREN ${ }^{1 *}$, Mediha KORKMAZ ${ }^{2}$, Nagehan DEMIRAL ${ }^{3}$ \\ ${ }^{1}$ Adnan Menderes University, Faculty of, Education, Aydın \\ 2. Ege University, Psychology Department, Izmir \\ ${ }^{3,}$ Ege University, Child psychiatry, İzmir
}

\begin{tabular}{l} 
ARTICLE INFO \\
\hline Article History: \\
Received \\
28.06 .2017 \\
Received in revised \\
form 14.12 .2017 \\
Accepted \\
24.12.2017 \\
Available online \\
28.12.2017
\end{tabular}

\begin{abstract}
In this study, it was aimed to investigate the relationship between psychometric intelligence level (WISC-R) and executive functions measured by Wisconsin Card Mapping Test (WKET) in gifted children. The sample of the study consisted of 50 students, 22 girls (44\%) and 28 boys (56\%), all of whom diagnosed as gifted at İmir Sıdıka Akdemir Science and Art Center (BILSEM). The Wisconsin Card Matching Test was applied individually to highly skilled children in a computer environment. The results of the study revealed that there is a relationship between WISC-R Verbal IQ and WKET in Verbal IQ 114-130 in gifted children, that there is no general relationship between Performance IQ and WKET and that WKET subscales differ significantly by age. An exploratory factor analysis was performed on the WKET scores in the sample group. Two basic factors were found as the result of the principal components and varimax rotation analyses. According to the PCA results, factor 1 has 6.27 eigenvalues and accounts for $57 \%$ of the total variance. These results indicate that the WKET factor structure is valid for gifted children.
\end{abstract}

(C) 2017AUJES. All rights reserved Keywords: Executive functions, gifted children, intelligence

\section{Extended Abstract}

\section{Purpose}

The dynamic and complex nature of information processing in the brain reveals the concept of executive functions in defining high-level cognitive functions. This concept includes mental functions such as reasoning, problem solving, mental flexibility, creativity, decision making, planning, disruptive interference, and confession of response (Funahashi, 2001; Lezak, 1995; Smith and Jonides, 1999;). The executive function is a term that is interdependent for complex cognitive processes and critical for purposeful, targeted behavior. (Lezak, Howieson, Loring, and Hannay, 2004).

The executive functions evaluated in stages such as reasoning, problem solving, mental flexibility, creativity, decision making are important issues when dealt with gifted

${ }^{*}$ Corresponding author's address: Adnan Menderes University, Education Faculty, Aydın e-mail: abildiren@adu.edu.tr 
children. Maker, Nielson and Rogers (1994), who had solved complex problems more rapidly than gifted individuals, showed better performance than the normal developmental individuals with attention and memory problem solving (Ludlow and Woodrum, 1982). Nonetheless, the moderate effect of intelligence on executive functioning in children remains uncertain (Arffa, 2007). Gifted children are expected to perform well in problem solving and reasoning. For this reason, it is aimed to investigate the relationship between psychometric intelligence level (WISC-R) and executive functions measured by Wisconsin Card Matching Test (WKET) in gifted children in this study.

\section{Method}

This research is a relational and quantitative study to examine the relationship between executive functions and psychometric intelligence level (WISC-R) measured by the Wisconsin Card Mapping Test (WKET). The relational screening model is a research model aimed at determining the presence and / or degree of exchange between two or more variables (Karasar, 2003). The sample of the study consisted of 50 students, 22 females (44\%) and 28 males (56\%), all of whom diagnosed as gifted at İzmir Sıdıka Akdemir Science and Art Center (BILSEM). According to the WISC-R intelligence test of the sample, the total intelligence score is over 130. The mean age of the sample is 10.66 and the standard deviation is .92. Data were analyzed with SPSS 17.0. Pearson product moment correlation analyses were performed between the WISC-R test subscales and the WKET scores. Unconnected samples between the age (8-10 years, 11-14 years) and WKET subscales of the sample were analyzed by t-test. In addition, exploratory factor analysis was performed on the WISC-R scores in the sample group.

\section{Results}

Pearson product moment correlation analyses were performed between the WISC-R test subscales and the WKET scores. In these analyses; WISC-R verbal IQ scores ranged from 114-130 IQ and 131-153 IQ scores in the WISC-R subscale of all samples and WISC-R all IQ scores of 130-140 IQ and 141-152 IQ scores in two groups By dividing the two group, the WISC-R performance IQ scores were made by dividing two grubs in the range of 117130 IQ and 131-145 IQ points.

In the range of verbal IQ 114-130; Correlations between WISC-R oral verbal subscales and total verbal IQ in the two groupings in the range of 114-130 IQ and 131-153 IQ, in Verbal IQ 114-130; $(P<.05, n=13)$ with total correct number, - $.56(p<.05, n=13)$ with repetitive response, -71 with total error number $)$, Non-repeating error $-.70(p<.01, n=13)$, repetitive error $-.57(p<.05, n=13)$, completed category number $.56(p<(P<.05, n=13)$, $.60(p<.05, n=13)$ with the conceptual response level, and .70 $(p<.01), N=13)$. Verbal IQ scores in the range of 141-130 showed significant correlations with WKET scores, whereas 
verbal IQ scores in the range of 131-153 did not show significant correlations with WKET scores. This result can be thought of as having homogeneous properties of gifted children (130 points and above), variance constriction and ceiling effects. WISC-R performance IQ scores were divided into two groups in the range of 117-130 IQ and 131-145 IQ, and no significant relation was found between WKET and WISC-R. Unconnected samples were ttested between the age (8-10 years, 11-14 years) and WKET subscales of the sample. According to the results; Repetitive response $t(48)=2.40, p<.05$, non-repetitive error $t(48)$ $=3.76, p<.01$, Repetitive error $t(48)=2.58, p<.05$, Completed $(48)=2,37, p<.01$, repetitive error percentage $t(48)=2.84, p<.01$ The first categorical completion was $t(48)=2,01, p<$ It is seen that there are significant differences between the number of responses used.

\section{Discussion}

The results of this study suggest that there is a relationship between WISC-R Verbal IQ and WKET in the range of Verbal IQ 114-130 in gifted children, that there is no significant association between WKET and Performance IQ, and that there is a significant age-specific difference between the WKET subscales and the WKET factor structure .

In this study, it was also found that the factor structure of WKET was valid for gifted children. With neuropsychological tests, the IQ relationship was found to be associated with the highest number of working memories (arithmetic, number sequence, cipher) (Arffa, 2007). In this study, WKET error scores of high intelligence scores were found to be negatively correlated with WISC-R arithmetic subtest. In the development of the frontal region, the ages of 11-12 years are the beginning of the abstract process period and stability is achieved in the age of 14-15 years. It is reported that the WKET scores obtained from 12 year old children and adults are the same (Chelune and Baer, 1986; Rosselli and Ardila, 1993).

\section{Conclusion}

It is thought that the normal IQ group and other executive function tests should be included in future studies (stroop, trail test, etc.), demonstrate the effect of the training, make the IQ range in the selected sample wide enough to show the IQ-WKET relationship and facilitate more comprehensive results in future studies. However, it should be noted that intelligence tests measure more basic neurocognitive functions, such as mental competence, and that new learners are more likely than children to be adults. It should be considered that it is not right to reach the conclusions about adults by looking at studies with children. 


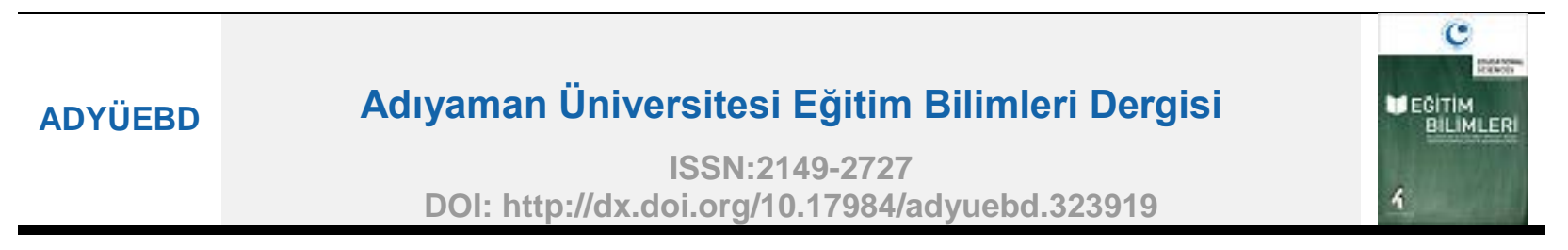

Üstün Yetenekli Çocuklarda Yönetici İşlevler ve Zeka Arasındaki İlişkiler

\begin{tabular}{|c|c|}
\hline MAKALE BÍLGİ & ÖZET \\
\hline $\begin{array}{l}\text { Makale Tarihçesi: } \\
\text { Alındı 28.06.2017 } \\
\text { Düzeltilmiş hali } \\
\text { alındı 14.12.2017 } \\
\text { Kabul edildi } \\
\text { 24.12.2017 } \\
\text { Çevrimiçi yayınlandı } \\
\text { 28.12.2017 }\end{array}$ & $\begin{array}{l}\text { Bu çalışmada üstün yetenekli çocuklarda Wisconsin Kart Eşleme Testi } \\
\text { (WKET) ile ölçülen yönetici işlevlerin psikometrik zeka düzeyi (WISC-R) ile } \\
\text { ilişkisinin araştırıması amaçlanmıştır. Araştırmanın örneklemi İzmir Sıdıka } \\
\text { Akdemir Bilim ve Sanat Merkezi'nde (BiLSEM) olan üstün yetenek tanısı } \\
\text { almış toplam } 50,22 \text { kız (\%44) ve } 28 \text { erkek (\%56) çocuktan oluşmaktadır. } \\
\text { Yönetici işlevlerin üstün yetenekli çocuklarda ölçümlenmesi Wisconsin Kart } \\
\text { Eşleme Testi (WKET) ile yapılmıştır. Wisconsin Kart Eşleme Testi üstün } \\
\text { yetenekli çocuklara bilgisayar ortamında bireysel olarak uygulanmıştır. } \\
\text { Araştırmanın sonuçları, üstün yetenekli çocuklarda Sözel IQ 114-130 } \\
\text { aralığında WISC-R Sözel IQ ile WKET arasında ilişki olduğunu, Performans } \\
\text { IQ ile WKET arasında yaygın ilişki olmadığını, WKET alt boyutları arasında } \\
\text { yaşa göre anlamlı farklılaşma olduğunu ortaya koymuştur. Örneklem } \\
\text { grubundaki WKET puanlarına açımlayıcı faktör analizi yapılmıştır. Temel } \\
\text { bileşenler ve varimax döndürmesi sonucunda } 2 \text { temel faktör bulunmuştur. } \\
\text { PCA sonuçlarına göre, } 1 \text {. faktör } 6.27 \text { özdeğere sahip olup, toplam varyansın } \\
\text { \%57'sini açıklamaktadır. Bu sonuçlar, WKET faktör yapısının üstün } \\
\text { yetenekli çocuklarda geçerli olduğunu ifade etmektedir. } \\
\text { @) 2017AUJES. Tüm hakları saklıdır } \\
\text { Anahtar Kelimeler: Üstün yetenekli çocuklar, yönetici işlevler, zeka }\end{array}$ \\
\hline
\end{tabular}

\section{Giriş}

Insan zekasının kavramsal bilgi, akıl yürütme, problem çözme, yaratıcılık, bellek ve algı gibi yüksek düzey zihinsel işlevlerle ilgili olduğu görüşü, zekanın bilişsel kuramlarının bir çoğunun temelini oluşturmaktadır (Luo, Thompson ve Detterman, 2006). Bu görüşlerden hareketle, zeka ve zihinsel işlevler arasındaki ilişkilerin incelenmesi pek çok araştırmaya konu olmuştur. Zeka ile ilişkisi incelenen zihinsel işlevlerden birisi de yönetici işlevlerdir.

Beyinde bilgi işlenişinin dinamik ve karmaşık doğası, yüksek düzeyli bilişsel işlevleri tanımlamada yönetici işlevler kavramını ortaya çıkarmıştır. Bu kavram akıl yürütme, sorun çözme, zihinsel esneklik, yaratıcılık, karar verme, planlama, bozucu etkiye karşı koyabilme, tepki ketlemesi gibi zihinsel işlevleri içermektedir (Funahashi, 2001, Lezak, 1995; Smith ve Jonides, 1999;). Yönetici işlev, karmaşık bilişsel süreçler için birbirine bağımlı olan ve amaçlı, hedefe yönelik davranış için kritik olan bir terimdir. (Lezak, Howieson, Loring, ve Hannay, 2004).

*Sorumlu yazarın adresi: Adnan Menderes Üniversitesi, Eğitim Fakültesi, Aydın, Türkiye e-posta: abildiren@adu.edu.tr 
Yönetici işlevlerin, bir hedefe ulaşmak için bir dizi yetenekten oluştuğu düşünülmektedir (Damasio, 1995; Stuss ve ark., 2005) ve bu yetenekler bir takım testlerle ölçülmektedir. Bunlardan bazıları, Fist-Edge-Palm Testi, Karşılıklı Motor Testi (The Reciprocal Motor Programme Test), Altı Element Testi (The Six Elements Test (SET)), Hayling Cümle Tamamlala Testi (The Hayling Sentence Completion Test), Brixton Uzamsal Testi (The Brixton Spatial Anticipation Test), Stroop Testi ve Wisconsin Kart Eşleştirme Testi (Wisconsin Card Sorting Test)'dir (Chan, Toulopoulou ve Chen, 2008).

Yönetici işlevler, bu testlerle beraber farklı zeka araştırmalarında IQ testleri ile farklı sonuçlarla ilişkilendirilmiştir. Seidenberg, Giordani, Berent ve Boll (1983) kavramsal problem çözme yeteneği, zihinsel verimlilik ve dil ile ilgili beceriler gerektiren nöropsikolojik ölçümlerin, IQ ile daha güçlü bir şekilde ilişkili olduğunu tespit etmiştir. Özellikle psikometrik IQ'yu yönetici işlevinin laboratuar görevleriyle ilişkilendiren Friedman ve ark. (2006), Wechsler yetişkin testi tüm zeka puanları ve alt testler ve Standart Progresif Matrisler arasında yüksek korelasyonlar tespit etmişlerdir. Johnstone, Holland ve Larimore, (2000) yetişkinler üzerine yaptığı araştırmada ise yürütücü işlev ile $I Q$ arasında önemli bir ilişki saptamamıştır. Türkiyede ise üstün yetenekli çocukların yönetici işlevleri üzerinde bir araştırmaya alan yazında rastlanmamıştır (Güçin ve Oruç, 2015).

Yönetici işlevler ile ilgili araştırmaların çoğu yetişkinler üzerine yapılmıştır. Çocuklar üzerinde yapılan araştırmalar sınırlıdır. Welsh, Pennington, and Grossier (1991) 6-12 yaş grubundaki çocuklarda IQ ile yönetsel işlevler arasında bir ilişki olmadığını ortaya koymuştur. Dikkat eksikliği hiperaktivite bozukluğu olan 6-16 yaş arasındaki çocukları inceleyen Riccio, Hall, Morgan ve Hynd (1994), Wechsler Çocuklar İçin Zeka Ölçeği (WISC-R) performans IQ'su ile Wisconsin Kart Eşleştirme Testi (WKET) arasında anlamlı ilişkiler tespit etmiştir.

Bireylerin zeka performansına göre de yönetici işlevler karşılaştırılmış ve farklı sonuçlar vurgulanmıştır. Ardila ve ark., (2000), Arffa ve ark., (1998), Baron (2003) ve Mahone ve ark., (2002) yüksek zeka puanlarına sahip bireylerin olduğu gruplarla yapılan çalışmalarda yönetici işlevler ile IQ arasında anlamlı ilişki bildirmişlerdir. Parsons (1984) bulguları zeka seviyesinin üst sınırlarında daha iyi performans elde edildiği yönündedir. Arffa'nın (2007) çalışmasında üstün yetenekli çocukların yönetici işlev testlerinde diğer çocuklardan daha başarılı olduğu ancak bu testlerin tüm IQ ile ilişkilerinin orta düzeyde olduğu bildirilmiştir. Arffa (1998) ve ark., çalışmasında WKET yineleyici hataları için yapılan varyans analizinde 130 IQ'nun üzerindeki çocukların normal ve normal üstü çocuklardan daha iyi olduğunu saptamıştır. Welsh ve ark., (1991) WKET yineleyici hataları ile IQ arasında ilişki bulamamıştır. Bu sonuçlar ele alındığında yönetici işlevlerin psikometrik zeka düzeyi ile ilişkili olduğu söylenebilir.

Akıl yürütme, sorun çözme, zihinsel esneklik, yaratıcılık, karar verme gibi aşamalar içerisinde değerlendirilen yönetici işlevler, üstün yetenekli çocuklar için ele alındığında önemli bir durum teşkil etmektedir. Üstün yetenekli bireylerin normal gelişim gösteren bireylere göre karmaşık problemleri daha hızlı çözdükleri Maker, Nielson ve Rogers (1994), dikkat ve hafıza bakımından problem çözmede normal gelişim gösteren bireylere göre daha iyi performans gösterdiği tespit edilmiştir (Ludlow ve Woodrum, 1982). Ancak buna rağmen zekanın çocuklarda yönetici işlev performansı üzerinde ılımlı etkisi belirsizliğini korumaktadır (Arffa, 2007). Üstün yetenekli çocukların problem çözme ve akıl yürütme de iyi performans göstermesi beklenen bir durumdur. $\mathrm{Bu}$ nedenle bu çalışmada üstün yetenekli çocuklarda 
Wisconsin Kart Eşleme Testi (WKET) ile ölçülen yönetici işlevlerin psikometrik zeka düzeyi (WISC-R) ile ilişkisinin araştırılması amaçlanmıştır.

\section{Yöntem}

\section{Araştırma Deseni}

Bu araştırma, Wisconsin Kart Eşleme Testi (WKET) ile ölçülen yönetici işlevler ve psikometrik zeka düzeyi (WISC-R) arasındaki ilişkileri incelemeye yönelik ilişkisel ve nicel bir çalışmadır. İlişkisel tarama modeli iki ve daha çok sayıdaki değişken arasında birlikte değişim varlığını ve/veya derecesini belirlemeyi amaçlayan araştırma modelleridir (Karasar, 2003).

\section{Çalışma Grubu}

Araştırmanın çalışma grubu İzmir Sıdıka Akdemir Bilim ve Sanat Merkezi'nde (BILSEM) olan üstün yetenek tanısı almış toplam 50, 22 kız (\%44) ve 28 erkek (\%56) çocuktan oluşmaktadır. Katılımcıların WISC-R zeka testine göre, tüm zeka puanı 130'un üzerindedir, yaş ortalaması 10.66 ve standart sapması.92'dir. Çalışma grubunun WISC-R zeka testi IQ ortalamaları tablo 1. de verilmiştir.

Tablo 1. Üstün Yetenekli Çocukların IQ Puanları

\begin{tabular}{llllll}
\hline & $\mathrm{n}$ & Min. & Max. & Ort. & Std.sapma \\
\hline Performans IQ & 46 & 117 & 145 & 132 & 6,25 \\
Sözel IQ & 46 & 114 & 153 & 134 & 7,58 \\
Tüm IQ & 46 & 130 & 152 & 136 & 5,31 \\
\hline
\end{tabular}

\section{Veri Toplama Araçları}

Wechsler Çocuklar İçin Zeka Ölçeği Geliştirilmiş Formu ( WISC-R): Wechsler tarafından 1949 yılında geliştirilen Wechsler Çocuklar İçin Zeka Ölçeği' nin ( WISC), 1974 yılında gözden geçirilmiş şekli olan WISC-R, sözel ve performans olmak üzere iki bölümden, her bölümde de toplam 6 alt testten oluşmaktadır. Araştırmada, tüm WISC-R test bataryasının sözel ve performans alt testleri(pratikte uygulanan 10 alt test) uygulanmıştır. Çalışma grubunda toplam 50 çocuk katılımcının Sözel IQ, Performan IQ ve Genel IQ puanlarına ulaşılabilmiş ancak yalnızca 20 çocuk katılımcının alt test puanları veri olarak kullanılmıştır. WISC-R'ın Türk çocukları üzerinde standardizasyonu Savaşır ve Şahin (1995) tarafından 6-16 yaş grubunda 1639 kişilik bir örneklem üzerinde gerçekleştirilmiştir. Testin iki-yarım güvenirliği sözel bölüm için 0.97 , performans bölümü için 0.93 ve toplam puan için 0.97 olarak bulunmuştur. Alt testler arası korelasyon değerleri, 0.51 ile 0.86 arasında değişmektedir (Savaşır ve Şahin, 1995).

Wisconsin Kart Eşleme Testi (WKET):Normal yetişkin bireylerde soyut akıl yürütme (abstraction) yeteneğini değerlendirmek amacıyla geliştirilen ilk eşleme testlerinden birisidir (Berg, 1948). Teste daha sonra son şeklini Heaton (1981) vermiştir. Ülkemizde de standardizasyon ve norm çalışmaları Karakaş ve Başar (1996) tarafından yapılmıştır. WKET ile kavramsallaştırma (conceptualization), stratejileri oluşturma ve iptal etme yeteneği, problem çözme, dikkati sürdürebilme, zihinsel esneklik gibi beynin yönetici işlevleri (executive function) olarak bilinen işlevleri değerlendirilmektedir (Heaton 1981; Lezak 1983). 
Yetişkin Türk örneklemi çalışmasında WKET'nin 2 temel özelliği ölçtüğü bildirilmektedir: esneklik/yineleme, kavramsallaştırma/ irdeleme (Karakaş, 2006).

1.Birinci faktör olan esneklik/yineleme: toplam doğru sayısı, yineleyici tepki sayısı, yineleyici hata, toplam hata sayısı, yineleyici hata yüzdesi, kavramsal tepki düzeyi yüzdesi, tamamlanan kategori sayısı.

2. faktör kavramsallaştırma/irdeleme 1. kategoriyi tamamlama, öğrenmeyi öğrenme, yineleyici olmayan hata.

WKET, her biri 64 tepki kartından oluşan iki kart destesi ve dört adet uyarıcı kartından oluşmaktadır. Bireysel olarak yapılan WCST uygulamasında, toplam 6 tane doğru eşleme kategorisi vardır. İlk doğru kategori renk, ikinci doğru kategori ise şekildir. WKET'te toplam 13 puan türü hesaplanmaktadır (Karakaş, 2006).

WKET1: toplam tepki sayısı(WKET2+WKET3)

WKET2: toplam yanlış sayısı

WKET3: toplam doğru sayısı

WKET4: tamamlanan kategori sayısı

WKET5: yineleyici tepki sayısı

WKET6: yineleyici hata sayısı

WKET7: yineleyici olmayan hata sayısı

WKET8: yineleyici hata yüzdesi

WKET9: ilk kategoriyi tamamlamada kullanılan tepki sayısı

WKET10: kavramsal düzey tepki sayısı

WKET11: kavramsal düzey tepki yüzdesi

WKET12:kurulumu sürdürmede başarısızlık

WKET13: öğrenmeyi öğrenme puanı

\section{Verilerin Toplanması}

WKET uygulamaları BILSEM Rehberlik ve Psikolojik Danışmanlık biriminde bilgisayar ortamında WKET bilgisayar versiyonu (Tien ve ark., 1989) ile ve psikolog eşliğinde yapılmıştır. WKET bilgisayar versiyonu üstün yetenekli çocuklara bireysel olarak uygulanmıştır.

\section{Verilerin Analizi}

Veriler SPSS 17.0 ile analiz edilmiştir. WISC-R testi alt boyutları ile WKET puanları arasında Pearson product moment korelasyon analizleri yapılmıştır. Örneklemin yaş (8-10 yaş, 11-14 yaş) ve WKET alt boyutları arasında yapılan bağlantısız örneklemler t-testi ile analiz edilmiştir. Ayrıca örneklem grubundaki WKET puanlarına açımlayıcı faktör analizi yapılmıştır.

\section{Bulgular ve Yorum}

Bu bölümde, WISC-R testi alt boyutları ile WKET puanları arasında Pearson product moment korelasyon analizleri sunulmuştur. WISC-R testi alt boyutları ile WKET puanları arasında Pearson product moment korelasyon analizleri yapılmıştır. $\mathrm{Bu}$ analizlerde; tüm örneklemde WKET puanları, WISC-R alt testleri arasında ve WISC-R tüm IQ puanları 130-140 IQ ve 141-152 IQ puan aralığında iki grup olarak, WISC-R sözel IQ puanları 114-130 IQ ve 131-153 IQ puan aralığında iki gruba bölünerek, WISC-R performans IQ puanları 117-130 IQ ve 131-145 IQ puan aralığında iki gruba bölünerek yapılmıştır. 
Sözel IQ 114-130 aralığında; WÇZÖ-R sözel IQ puanları 114-130 IQ ve 131153 IQ puan aralığında iki gruba bölündüğünde WKET ve WISC-R sözel alt testler ile toplam sözel IQ arasındaki korelasyonlar, Sözel IQ 114-130 aralığında; Toplam doğru sayısı ile $.60(p<.05, n=13)$, Yineleyici tepki ile $-.56(p<.05, n=13)$, Toplam hata sayısı ile -.71 $(p<.01, n=13)$, Yineleyici olmayan hata ile $-.70(p<.01, n=13)$, Yineleyici hata ile -.57 $(p<.05, n=13)$, Tamamlanan kategori sayısı .ile .56 $(p<.05, n=13)$, Yineleyici hata \% ile -.60 ( $p<.05, n=13)$, Kavramsal tepki düzeyi ile .60 $(p<.05, n=13)$, Öğrenmeyi öğrenme ile $.70(p<.01, n=13)$ olarak tespit edilmiştir.114-130 aralığındaki Sözel IQ puanları WKET puanlarıyla anlamlı korelasyonlar göstermiş, buna karşın 131-153 aralığındaki sözel IQ puanları WKET puanlarıyla anlamlı korelasyonlar göstermemiştir. Bu sonuç üstün yetenekli çocukların (130 puan ve üzeri) homojen özellikler göstermesi, varyans daralması ve tavan etkileri biçiminde düşünülebilir. WISC-R performans IQ puanları 117-130 IQ ve 131-145 IQ puan aralığında iki gruba bölünerek, WKET ve WISC-R arasında anlamlı düzeyde yaygın ilişkiler saptanmamıştır (Tablo 2).

Tablo 2. WISC-R tüm IQ puanları 130-140 IQ ve 141-152 IQ puan aralığında iki grup olarak bölündüğünde WKET VE WISC-R alt testleri arasındaki korelasyonlar.

\begin{tabular}{|c|c|c|c|c|}
\hline WKET BOYUTLAR & Aritmetik & Benzerlik & $\begin{array}{l}\text { Resim } \\
\text { Tamam }\end{array}$ & Küpler \\
\hline Toplam doğru sayısı & $\begin{array}{c}.67 \\
(P<.01, n=14)\end{array}$ & & & \\
\hline Toplam hata sayısı & $\begin{array}{c}-.65 \\
(P<.05, n=14)\end{array}$ & & & \\
\hline Yineleyici tepki & $\begin{array}{c}-.76 \\
(P<.01, n=14)\end{array}$ & & & \\
\hline Yineleyici hata & $\begin{array}{c}-.71 \\
(P<.01, n=14)\end{array}$ & & & $\begin{array}{c}-.54 \\
(P<.05, n=14)\end{array}$ \\
\hline Yineleyici hata \% & $\begin{array}{c}-. .74 \\
(P<.01, n=14)\end{array}$ & & & \\
\hline $\begin{array}{l}\text { 1.Kategoriyi } \\
\text { tamamlama }\end{array}$ & $\begin{array}{c}-.61 \\
(P<.05, n=14)\end{array}$ & & & \\
\hline
\end{tabular}

GENEL IQ 141-152 ARALIĞINDA

Tamamlanan kategori

sayısı

\section{.84}

$(P<.05, N=6)$

\section{.88}

Öğrenmeyi öğrenme

$(P<.05, N=6)$

Örneklemin yaş (8-10 yaş, 11-14 yaş) ve WKET alt boyutlarından alınan toplam puanlara göre ortalamaları arasında anlamlı bir farklılaşma olup olmadığı bağlantısız örneklemler t-testiyle incelenmiştir. . Sonuçlara göre; yaş gruplarının WKET alt boyutlarından toplam doğru sayısı $(\mathrm{t}(48)=4,04, \mathrm{p}<.001)$, yineleyici tepki ( $\mathrm{t}(48)=2,40, \mathrm{p}<.05)$, Yineleyici olmayan hata $(\mathrm{t}(48)=3,76, \mathrm{p}<.001)$, Yineleyici hata ( $\mathrm{t}(48)=2,58, \mathrm{p}<.05)$, Tamamlanan kategori sayısı $(\mathrm{t}(48)=3,37, \mathrm{p}<.01)$, ve Yineleyici hata yüzdesi(t(48)=2,84), tepki sayıları arasında istatistiksel olarak anlamlı farklılaşmaların olduğu görülmüştür (Tablo 3). 
Katılımcılar WISC-R toplam puanlarına göre; WISC-R tüm IQ puanları 130140 IQ ve 141-152 IQ puan aralığı, WISC-R sözel IQ puanları 114-130 IQ ve 131-153 IQ puan aralığı ve WISC-R performans IQ puanları 117-130 IQ ve 131-145 IQ puan aralığında yeniden gruplandırılmışlardır.WKET toplam puanlarının WISC-R toplam puanları üzerinden yapılan grup değişkenine göre bağlantısız örneklem t-testi sonuçlarına göre hiçbir istatistiksel anlamlı farklılaşma bulunmamıştır.

Tablo 3. 8-10 yaş ve 11-14 yaş gruplarılyla WKETalt test toplam puan ortalamaları ttest sonuçları

\begin{tabular}{|c|c|c|c|c|c|c|c|}
\hline $\begin{array}{l}\text { Wket alt testler } \\
\text { toplam puanları }\end{array}$ & $\begin{array}{l}\text { Yaş } \\
\text { grupları }\end{array}$ & $\mathbf{n}$ & Ortalama & $\begin{array}{c}\text { Std. } \\
\text { Sapma }\end{array}$ & Sd & $\mathbf{t}$ & $\mathbf{p}$ \\
\hline \multirow[t]{2}{*}{ Toplam doğru sayısı } & 8-10 yas & 20 & 93,1 & 8,18 & 48 & 4,04 & .000 \\
\hline & $11-15$ yas & 30 & 101,6 & 6,73 & & & \\
\hline \multirow[t]{2}{*}{ Toplam hata } & 8-10 yas & 20 & 34,4 & 7,70 & 48 & 2,02 & ,049 \\
\hline & $11-15$ yas & 30 & 28,4 & 11,59 & & & \\
\hline \multirow[t]{2}{*}{ Yineleyici tepki } & 8-10 yas & 20 & 18,9 & 6,28 & 48 & 2,40 & ,020 \\
\hline & $11-15$ yas & 30 & 15,1 & 4,93 & & & \\
\hline \multirow{2}{*}{$\begin{array}{l}\text { Yineleyici olmayan } \\
\text { hata }\end{array}$} & 8-10 yas & 20 & 16,9 & 4,39 & 48 & 3,76 &, 000 \\
\hline & $11-15$ yas & 30 & 12,3 & 4,06 & & & \\
\hline \multirow[t]{2}{*}{ Yineleyici hata } & 8-10 yas & 20 & 17,6 & 5,33 & 48 & 2,58 & ,013 \\
\hline & $11-15$ yas & 30 & 14,2 & 4,08 & & & \\
\hline \multirow{2}{*}{$\begin{array}{l}\text { Tamamlanmış } \\
\text { kategori }\end{array}$} & 8-10 yas & 20 & 5,5 & 1,84 & 48 & 3,37 &, 001 \\
\hline & $11-15$ yas & 30 & 7,1 & 1,39 & & & \\
\hline \multirow{2}{*}{$\begin{array}{l}\text { Yineleyici hata } \\
\text { yüzdesi }\end{array}$} & $8-10$ yas & 20 & 13,7 & 4,16 & 48 & 2,84 & ,006 \\
\hline & $11-15$ yas & 30 & 10,8 & 3,11 & & & \\
\hline \multirow{2}{*}{$\begin{array}{l}\text { 1. Kategoriyi } \\
\text { tamamlama }\end{array}$} & 8-10 yas & 20 & 20,2 & 13,18 & 48 & 2,01 & ,050 \\
\hline & $11-15$ yas & 30 & 14,6 & 6,18 & & & \\
\hline \multirow{2}{*}{$\begin{array}{l}\text { Kurulumu } \\
\text { sürdürememe }\end{array}$} & 8-10 yas & 20 & 2,15 & 1,26 & 48 & ,32 & ,896 \\
\hline & $11-15$ yas & 30 & 2,10 & 1,34 & & & \\
\hline
\end{tabular}

Örneklem grubundaki WKET puanlarına açımlayıcı faktör analizi yapılmıştır. Faktör analizi yapmaya uygunluk düzeyi olan KMO değeri 0.84 olarak saptanmış ve korelasyon matrisinin birim matris olmadığı varsayımı olan Barlet's testi istatistiksel olarak anlamlı bulunmuştur $\left(X^{2}=696.5, s d=55, p<.001\right)$. Temel bileşenler ve varimaks döndürmesi sonucunda 2 temel bileşen bulunmuştur. Temel bileşenler analizi 
sonuçlarına göre, 1. faktör 6.27 özdeğere sahip olup, toplam varyansın \%57'sini açıklamaktadır. 1. faktördeki (öğrenmeyi öğrenme ve kurulumu sürdürememe) dışındaki tüm diğer puanların yüksek faktör yüklerine sahip olduğu görülmektedir. Bu sonuçlar, WKET faktör yapısının üstün yetenekli çocuklarda geçerli olduğunu ifade etmektedir (Tablo 4).

Tablo 4. WKET Temel Bileşenler Faktör Analizi Sonuçları

Bileşen1 Bileşen2

\begin{tabular}{lcc}
\hline Kavramsal tepki düzeyi \% &,- 972 & \\
\hline Toplam doğru sayısı &,- 968 & \\
\hline Yineleyici hata \% &, 897 &, 439 \\
\hline Yineleyici hata &, 894 & \\
\hline Yineleyici tepki &, 863 & \\
\hline Tamamlanan kategori sayısı &,- 821 & \\
\hline Yineleyici olmayan hata &, 728 &,- 840 \\
\hline Toplam hata sayısı &, 676 &, 787 \\
\hline 1. kategoriyi tamamlama &, 597 & 1.57 \\
\hline Kurulumu sürdürememe & & $\% 14$ \\
\hline Öğrenmeyi öğrenme & 6.27 & \\
\hline Özdeğer & $\% 57$ & \\
\hline Top.var.açık.\% & & \\
\hline
\end{tabular}

\section{Tartışma}

Sternberg (1985), yönetici işlevleri, genel zeka veya g faktörünün bir yansıması olarak ele almıştır. Oysa yönetici işlevleri ölçen testlerle zeka ilişkisini inceleyen çalışmaların sonuçları değişkendir. Bazı çalışmacılar yönetici işlevlerle zeka arasında anlamlı ilişkiler bildirmezken bazıları da tersini belirtmiştir. Özellikle hayvan deneyleri, frontal lob çalışmaları psikometrik zekanın yönetici işlevlerden farklı olduğunu göstermiştir.

Yetişkinlerdeki frontal lob yaralanmaları ile ilgili çalışmalarda IQ'nun anlamlı düzeyde azalmadığı bildirilmiş ancak özellikle çocuklarda (Grattan ve Eslinger, 1991) bunun daha çok frontal yaralanmanın olduğu yaş ve bunun şiddeti ile ilgili olabileceği belirtilmiştir (Warrington, James ve Maciejewski, 1986). Heaton (1981), WKET'nin orijinal formuna ilişkin standardizasyon çalışmasında, WKET puanları ile WAIS Toplam Zeka puanı arasında düşük korelasyonlar belirtmiştir. Ardila ve ark., (1999) 
13-16 yaş arası normal çocuklarda yaptığı çalışmada: WKET'nin yineleyici hataları ile WISC-R'ın sözel ve toplam IQ arasında düşük oranda negatif korelasyon saptamıştır. Arffa (1998) sağlıklı yetişkinlerde IQ ile WKET ilişkisi bulurken Boone ve ark., (1993) tersini bulmuştur. Riccio (1984) 9-11 yaş arası Hiperaktivite ve dikkat eksikliği (DEHB) olan çocuklarla yaptığı çalışmada IQ ile WKET arasında ilişki bulmuştur.

Şahin (1996) WKET ile WAIS arasında anlamlı düzeyde çok düşük ilişki bildirmiştir. WKET toplam yineleyici hata sayısı toplam zeka puanında gözlenen varyansın \%9.2sini, performans zeka puanında 3,9'unu açıklamıştır. DEHB önemli yer tutan yönetici işlevlerle WISC-R puanları arasındaki düşük ilişki bildirilmektedir (Ardilla ve ark., 1998; Scheres ve ark., 2004; Sergeant ve ark., 2002). WKET puanları ile Raven Standart Progresif Matrisler Testi (RSPM) puanlarının birlikte oluşturdukları faktör örüntüsü incelenmiş, RSPM için hesaplanan puanlar, WKET puanlarının yüklendiği faktörler altında yer almamıştır. Araştırmacılar, sonucu WKET'nin zeka testlerinde ölçülen özelliklerden farklı bir yetenek alanını ölçtüğü şeklinde yorumlamışlardır (Karakaş ve Başar 1993; Karakaş ve ark., 1996; Boone ve ark., 1993) Bu bulgu aynı zamanda WKET Türk Formun ölçmesi beklenen özelliği geçerli olarak ölçtüğünü de belirtmektedir (Karakaş ve ark., 1999).

Bu çalışmada da WKET 'nin faktör yapısının üstün yetenekli çocuklar içinde geçerli olduğu saptanmıştır. Nöropsikolojik testlerle IQ ilişkisi en fazla çalışan bellek (aritmetik, sayı dizisi, şifre) ile ilişkili bulunmuştur (Arffa, 2007). Bu çalışmada da tüm zeka puanı yüksek olguların WKET hata puanları WISC-R aritmetik alt testi ile negatif yönde ilişkili bulunmuştur. Frontal bölge gelişiminde 11-12 yaş soyut işlemler döneminin başlangıcı olup 14-15 yaşlarında kararlılık kazanılmaktadır.12 yaşındaki çocuklarla yetişkinlerden elde edilen WKET puanların aynı olduğu bildirilmektedir (Chelune ve Baer, 1986; Rosselli ve Ardila, 1993).

Yaş ile IQ etkileşimine bakılarak WKET ile (yineleyici hata) ilgili çalışmalarda; üstün yetenekli gençler sadece genç yaş grubunda üstün yetenekli ve parlak çocuklardan daha başarılı olmuşlardır. Ortalamanın üzerindeki grup ileriki yaşlarda daha iyi performans gösterirken daha büyük üstün yetenekli çocuklar daha küçük üstün yetenekli çocuklardan daha iyi test performansı göstermemiştir (Arffa 1998). Bu WKET üzerinde tavan etkisi olarak açıklanabilir.

Yalçın ve Karakaş'ın (2007) çalışmasında; WKET'inde 8-10 yaş çocukların, 11-14 yaş çocuklardan daha az doğru davranım ve daha fazla hata yaptıkları bulunmuştur. Yalçın'ın çalışmasında WKET performansı ve yönetici işlevler açısından yaşla birlikte niceliksel farklar olduğunu göstermektedir. Aynı zamanda büyük yaş grubundaki faktör yapısı yetişkin faktör yapısıyla aynıdır.

Üstün yetenekli gençler en iyi yetişkin ortalama puanlarını aşmaktadır. Parlak ve üstün IQ' lu 9-11 yaş ile yetişkin ortalama performans aynı seviyede bulunmuştur (Arffa 1998). Bu çalışmada da Yalçın'ın çalışmasına karşıt olarak her iki yaş grubunda da WKET'in puanları aynı faktör örüntüsü göstermiştir. Bu sonuç bize yüksek zekalı çocuklarda IQ'nun etkisini düşündürtebilir. Üstün yetenekli çocuklarda yaşla birlikte niceliksel farklar olmakla birlikte niteliksel anlamda bir fark görülmemekte, her iki yaş grubunda da benzeri davranış paterni sergilenmektedir. Oysaki normal çocuklarda niteliksel değişiklik yaşla birlikte değişmekte ve büyük yaşlarda yetişkinlere benzer patern göstermektedir. 


\section{Sonuç}

$\mathrm{Bu}$ araştırmanın sonuçları, üstün yetenekli çocuklarda Sözel IQ 114-130 aralığında WISC-R Sözel IQ ile WKET arasında ilişki olduğunu, Performans IQ ile WKET arasında yaygın ilişki olmadığını, WKET alt boyutları arasında yaşa göre anlamlı farklılaşma olduğunu ve WKET faktör yapısının üstün yetenekli çocuklarda geçerli olduğunu ortaya koymuştur.Yönetici işlevler çok sayıda fonksiyonu kapsamaktadır: Basit düzeyde tepki inhibisyonundan karmaşık düzeyde problem çözmeye kadar gelişimsel aşamalarda zeka ile ilişkisini gözlemek önemlidir. Yönetici işlevler "zeka davranışının" elementlerini içermeyebilirler. Yönetici işlev testleri "zekanın çok önemli elementlerine duyarlı olmayabilir. Psikometrik zeka testleri zekayı değerlendirmede yetersiz olabilir. Psikometrik $g$ ve yönetici işlevler arasındaki farkın aydınlatılmasının psikometrik ve pratik zeka arasındaki ayrımın anlaşılmasında önemli olduğu belirtilmektedir (Crinella ve Yu, 2000). WKET ile IQ arasındaki ilişkinin anlamlı olmaması üstün yetenekli çocuklarda küçük yaş grubunda bile etkili düzeyde bir başarının olması, yönetici işlevlerin çözümünde yüksek zekalı çocukların diğer çocuklarla aynı stratejileri kullanmaları ile açıklanmaktadır.

Normal IQ grubun ve diğer yürütücü işlev testlerinin ileriki çalışmalarda yer alması (stroop, iz sürme testi vb), eğitimin etkisinin gösterilmesi, seçilen örneklemdeki IQ ranjının IQ-WKET ilişkisini gösterecek kadar geniş olması gelecekteki yapılacak araştırmalarda daha kapsamlı sonuçlar alınmasını kolaylaştıracağı düşünülmektedir. Ancak şunu da belirtmek gerekir ki zeka testlerinin mental yeterlilik gibi daha temel nörokognitif fonksiyonları ölçmesi ve yeni öğrenmenin çocuklarda yetişkinlere göre daha fazladır. Çocuklarla yapılan çalışmalar bakarak yetişkinlerle ilgili sonuçlara varmak doğru olmayacağı göz önünde bulundurulmalıdır.

\section{Kaynaklar}

Ardila, A., Pineda, D., ve Rosselli, M. (2000). Correlation between intelligence test scores and executive function measures. Archives of clinical neuropsychology, 15(1), 31-36.

Ardila, A., Ostrosky-Solis, F., Rosselli, M., ve Gómez, C. (2000). Age-related cognitive decline during normal aging: the complex effect of education. Archives of clinical neuropsychology, 15(6), 495-513.

Arffa, S. (2007). The relationship of intelligence to executive function and nonexecutive function measures in a sample of average, above average, and gifted youth. Archives of Clinical Neuropsychology, 22(8), 969-978.

Arffa, S., Lovell, M., Podell, K., ve Goldberg, E. (1998). Wisconsin Card Sorting Test performance in above average and superior school children: Relationship to intelligence and age. Archives of Clinical Neuropsychology, 13(8), 713-720.

Berg, E. A. (1948). A simple objective technique for measuring flexibility in thinking. The Journal of general psychology, 39(1), 15-22.

Boone, K. B., Ghaffarian, S., Lesser, I. M., Hill-Gutierrez, E., ve G Berman, N. (1993). Wisconsin Card Sorting Test performance in healthy, older adults: Relationship to age, sex, education, and IQ. Journal of Clinical Psychology, 49(1), 54-60. 
Chan, R. C., Shum, D., Toulopoulou, T., ve Chen, E. Y. (2008). Assessment of executive functions: Review of instruments and identification of critical issues. Archives of clinical neuropsychology, 23(2), 201-216.

Chelune, G. J., ve Baer, R. A. (1986). Developmental norms for the Wisconsin Card Sorting test. Journal of Clinical and Experimental Neuropsychology, 8(3), 219228.

Crinella, F. M., ve Yu, J. (2000). Brain mechanisms in problem solving and intelligence: $g$ and executive function. Intelligence, 27, 1-29.

Damasio, A. R. (1995). Toward a neurobiology of emotion and feeling: Operational concepts and hypotheses. The Neuroscientist, 1(1), 19-25.

Friedman, N. P., Miyake, A., Corley, R. P., Young, S. E., DeFries, J. C., ve Hewitt, J. K. (2006). Not all executive functions are related to intelligence. Psychological Science, 17(2), 172-179.

Funahashi, S. (2001). Neuronal mechanisms of executive control by the prefrontal cortex. Neuroscience research, 39(2), 147-165.

Grattan, L. M., ve Eslinger, P. J. (1991). Frontal lobe damage in children and adults: A comparative review. Developmental Neuropsychology, 7(3), 283-326.

Güçin, G. ve Oruç, Ş. (2015). Türkiye'de üstün yetenekliler ve üstün zekâlılar alanında yapılmış akademik çalışmaların çeşitli değişkenler açısından değerlendirilmesi. Adıyaman Üniversitesi Eğitim Bilimleri Dergisi, 5(2), 113135.

Heaton, R. K. (1981). Wisconsin card sorting test manual. Psychological assessment resources.

Johnstone, B., Holland, D., ve Larimore, C. (2000). Language and academic abilities. In G. Groth-Marnat (Ed.), Neuropsychological assessment in clinical practice: A guide to test interpretation and integration (pp. 335-354). New York, NY: John Wiley \& Sons, Inc.

Karakaş, S., ve Başar, E. (1993). Nöropsikolojik değerlendirme araçlarının standardizasyonu nöropsikolojik ölçümlerin elektrofizyolojik ölçümlerle ilişkileri. Proje No: TÜBITAK-TBAG, 17(2).

Karakaş, S., Eski, R., ve Başar, E. (1996). Türk kültürü için standardizasyonu yapılmış nöropsikolojik testler topluluğu: BİLNOT Bataryası. 32. Ulusal Nöroloji Kongresi Kitabı. Türk Nöroloji Dergisi ve Bakırköy Ruh ve Sinir Hastalıkları Hastanesi. İstanbul, Ufuk Mat.

Karakaş, S., Irak, M., ve Ersezgin, Ö. U. (1998). Wisconsin Kart Eşleme Testi (WCST) ve Stroop Testi TBAG formu puanlarının test içi ve testler-arası ilişkileri. X. Ulusal Psikoloji Kongresi özet kitabı, 44.

Karakaş, S., \& Kafadar, H. (1999). Şizofrenideki bilişsel süreçlerin değerlendirilmesinde nöropsikolojik testler: Bellek ve dikkatin ölçülmesi. Şizofreni dizisi, 2(4), 132-152.

Karasar, N. (2003). Bilimsel araştırma yöntemi. Ankara: Nobel Yayın Dağıtım.

Lezak, M. D. (1983). Verbal functions. In Neuropsychological Assessment (pp. 312341). Oxford University Press, New York, NY. 
Lezak, M.D. (1995) Neuropsychological Assessment, 3rd edn., Oxford University Press, New York.

Lezak, M. D., Howieson, D. B., Loring, D. W., ve Hannay, H. J. (2004). Neuropsychological assessment (4th ed.). Oxford University Press

Ludlow, B., ve Woodrum, D. T. (1982). Problem-solving strategies of gifted and average learners on a multiple discrimination task. Gifted child quarterly, 26(3), 99-104.

Luo, D., Thompson, L. A., ve Detterman, D. K. (2006). The criterion validity of tasks of basic cognitive processes. Intelligence, 34(1), 79-120.

Mahone, E. M., Cirino, P. T., Cutting, L. E., Cerrone, P. M., Hagelthorn, K. M., Hiemenz, J. R., ... ve Denckla, M. B. (2002). Validity of the behavior rating inventory of executive function in children with ADHD and/or Tourette syndrome. Archives of Clinical Neuropsychology, 17(7), 643-662.

Maker, C. J., Nielson, A. B., ve Rogers, J. A. (1994). Giftedness, diversity, and problem -solving. Teaching Exceptional Children, 27(1), 4-19.

Parsons, E. J. C. (1984). An investigation of appropriate neuropsychological assessment procedures with adults in the higher intelligence ranges. Dissertation Abstracts International, 45(5), 1592B

Rosselli, M., \& Ardila, A. (1993). Developmental norms for the Wisconsin Card Sorting Test in 5-to 12-year-old children. The Clinical Neuropsychologist, 7(2), 145-154.

Savaşır, I. (1995). Wechsler çocuklar için zekâ ölçeği uygulama kitapçı̆̆ı,[çev. Savaşır, I.; Şahin, N.]. Ankara: Türk Psikologlar Derneği.

Scheres, A., Oosterlaan, J., Geurts, H., Morein-Zamir, S., Meiran, N., Schut, H., ... ve Sergeant, J. A. (2004). Executive functioning in boys with ADHD: primarily an inhibition deficit?. Archives of Clinical Neuropsychology, 19(4), 569-594.

Seidenberg, M., Giordani, B., Berent, S., ve Boll, T. (1983). IQ level and performance of the Halstead-Reitan Neuropsychological Test battery for older children. Journal of Consulting and Clinical Psychology, 51(3), 406-413

Sergeant JA, Geurts H, ve Oosterlaan J (2002) How specific is a deficit of executive functioning for attention-deficit/hyperactivity disorder? Behav Brain Res, 130: 3-28.

Smith, E. E., ve Jonides, J. (1999). Storage and executive processes in the frontal lobes. Science, 283(5408), 1657-1661.

Sternberg, R. J. (1985). Beyond IQ: A triarchic theory of human intelligence. CUP Archive.

Stuss, D. T., Alexander, M. P., Shallice, T., Picton, T. W., Binns, M. A., Macdonald, R., et al. (2005). Multiple frontal systems controlling response speed. Neuropsychologia, 43, 396-417.

Şahin, A. (1996). Bir grup üniversite öğrencisinde nöropsikolojik testlerle zeka testi arasındaki ilişkilerin incelenmesi. Hacettepe Üniversitesi, Sosyal Bilimler Enstitüsü, yayınlanmamış yüksek lisans tezi, Ankara. 
Tien, A., Schlaepfer, T., Spevack, T., Jones, D., Strauss, M., ve Pearlson, G. (1989). Computerization of the Wisconsin Card Sorting Test. Unpublished manuscript.

Yalçın, K., ve Karakaş, S. (2007). Wisconsin kart eşleme testi performansında gelişimin niceliksel ve niteliksel etkileri. Çocuk ve gençlik ruh sağlığı dergisi, 14(1), 24-32.

Welsh, M. C., Pennington, B. F., ve Groisser, D. B. (1991). A normative-developmental study of executive function: A window on prefrontal function in children. Developmental neuropsychology, 7(2), 131-149.

Warrington, E. K., James, M., ve Maciejewski, C. (1986). The WAIS as a lateralizing and localizing diagnostic instrument: A study of 656 patients with unilateral cerebral lesions. Neuropsychologia, 24(2), 223-239. 